\title{
Encouragement for Faculty to Implement Vision and Change
}

\author{
Caylyn Harvey, ${ }^{\dagger}$ Kristen Eshleman, ${ }^{\ddagger}$ Kyosung Koo, ${ }^{\ddagger}$ Kevin G. Smith, ${ }^{\dagger}$ \\ Christopher J. Paradise, ${ }^{\dagger}$ and A. Malcolm Campbell ${ }^{\dagger *}$ \\ 'Biology Department and ₹Information Technology Services, Davidson College, Davidson, \\ NC 28035
}

\begin{abstract}
The seminal report Vision and Change outlined improvements necessary for undergraduate biology courses to accomplish widely recognized learning objectives. Over the past 8 years, we have developed a two-semester introductory biology course that incorporates the core concepts and competencies recommended in Vision and Change. Using published research on how students learn, we focused our efforts on three main areas of change: pedagogy, course content, and technology. We introduced active-learning strategies to improve our classroom environments, wrote an e-textbook that provides students with the tools they need to construct their own knowledge, and employed an online learning hub to assist students who needed extra support. The redesigned courses have been well received by students, and we have seen good student learning outcomes. The purpose of this essay is to demonstrate to faculty that Vision and Change's recommendations are feasible and students welcome the improvements.
\end{abstract}

\section{INTRODUCTION}

"My first instinct is to resist change at all costs." Faculty who want to revise the curriculum will often encounter a retort like this, which can be rephrased to "You cannot make me change the way I teach." Over the past 20 years, the biology education community has called for improvements in the undergraduate biology curriculum, with special emphasis on introductory courses (National Research Council [NRC], 2003; American Association for the Advancement of Science [AAAS], 2011). Many white papers and research articles have proposed specific recommendations for improvements in the areas of pedagogy, course content, and educational technology. Vision and Change (AAAS, 2011) described five core concepts that should be incorporated into undergraduate biology education: evolution, structure and function, information, energy, and systems. The same report also outlined six core competencies that biology students should master through their experience: apply the process of science, use quantitative reasoning, employ modeling and simulation, experience the interdisciplinary nature of science, communicate with other disciplines, and integrate science and society. Vision and Change's recommendations highlight an active-learning environment in which instructors lead students to construct their own knowledge base and emphasize concepts and skills over details (NRC, 2000).

At this stage in biology education, we have ample advice about what to do to help students learn. The challenge that rank-and-file faculty face is how to implement the recommendations of Vision and Change in their courses. Over the past 8 years, we gradually built a two-semester introductory biology course from the ground up (Barsoum et al., 2013; Prestwich and Sheehy, 2015; Wagner et al., 2015). We started to develop our pedagogical approach by first reading the literature on how people learn (NRC, 2000; Caldwell, 2007; Tanner, 2009; Smith et al., 2011a,b). We mapped out the learning objectives and assembled the concepts and competencies to match our objectives (Prestwich and Sheehy, 2015). In the process, we developed a data-centric
Jose Herrera, Monitoring Editor Submitted March 16, 2016; Revised May 30, 2016; Accepted May 31, 2016 DOI:10.1187/cbe.16-03-0127

CBE Life Sci Educ December 1, 2016 15:es7 *Address correspondence to: A. Malcolm Campbell (macampbell@davidson.edu). A.M.C. and C.J.P. wrote the textbook described in this study. Other books based on the same principles may accomplish the same outcomes, although no such book is commercially available at this time.

(C) 2016 C. Harvey et al. CBE-Life Sciences Education (C) 2016 The American Society for Cell Biology. This article is distributed by The American Society for Cell Biology under license from the author(s). It is available to the public under an Attribution-Noncommercial-Share Alike 3.0 Unported Creative Commons License (http://creativecommons.org/licenses/ by-nc-sa/3.0)

"ASCB@" and "The American Society for Cell Biology ${ }^{\circledR}$ " are registered trademarks of The American Society for Cell Biology. 
teaching approach that we refer to as "Data Into Biological Sciences" (DIBS)-teaching. Our main goals in developing this approach were to help students construct their own knowledge and think like scientists (Uno, 1999; NRC, 2000). We incorporated mathematics, statistics, and modeling in the form of BioMath Explorations. We included connections to the "real world" with Ethical, Legal, Social Implication readings. The last piece of our redesigned course was employing appropriate technology to help students learn, especially those who might otherwise be left behind. We fully integrated active learning into the course; constructed a new curriculum to address the content and competencies; and chose Echo360, a lecture-capture, active-learning, and analytics platform, as our online learning hub to augment student learning. All students in our courses had equal access to every component described in this essay.

We here summarize how we wove these strands of change into our vision of introductory biology. We fully acknowledge that our course is not the only approach and may not be the best approach in every context (Rowe et al., 2015; Flaherty, 2016). Nevertheless, we hope this essay will encourage more faculty and departments to overhaul their introductory courses by applying the good advice and methods that have been described, tested, and confirmed repeatedly (Caldwell, 2007; Tanner, 2009; Smith et al., 2011a,b; Barsoum et al., 2013; Freeman et al., 2014; Gross et al., 2015; Jensen et al., 2015). Other campuses with course enrollments exceeding 100 students have already adopted our approach, and two additional campuses with course enrollments of more than 200 will launch their versions in the Fall of 2016. We provide some details on our methodology and student outcomes for three key areas: pedagogy, course content, and technology.

\section{PEDAGOGY}

Active-learning pedagogy in the classroom is the focus of most research in undergraduate biology education. Vision and Change and many research papers have promoted in-class work based on active learning instead of lectures (Tanner, 2009; AAAS, 2011; Freeman et al., 2014; Jensen et al., 2015). Active learning engages students and allows them to develop the core competencies that Vision and Change described and helps them retain the information longer because they construct their own knowledge. Freeman and coworkers conducted a meta-analysis of research comparing active learning versus passive lectures in science, technology, engineering, and mathematics (STEM) courses (Freeman et al., 2014). Regardless of course size, type of institution, or discipline, students in active-learning courses performed better and failed less than students in traditional lecture courses. Consistent with Freeman and coworkers' analysis, our students improved their ability to interpret data, retained core concepts longer, and altered their perception of biology to recognize the discipline is not based on memorization of "facts" but relies instead on analysis, synthesis, and higher-order reasoning (Barsoum et al., 2013).

Our approach includes cold calling students (calling on students regardless of whether they have raised their hands), having students work in small groups, and involving students in activities such as drawing on whiteboards. Cold calling effectively flips the class, because students come to class prepared and they actively reinforce in class what they have already studied (Gross et al., 2015; Jensen et al., 2015). Cold calling, on groups or individuals, is a very effective method of ensuring that students not only read before class but also make an effort to understand what they read (Dallimore et al., 2012). Holding students accountable each class facilitates students' construction of their own knowledge, which is how people learn best (NRC, 2000; Tanner, 2009; Moravec et al., 2010; Smith et al., 2011b; Freeman et al., 2014). Although some students initially expressed some anxiety about the method, 29 out of 59 Fall 2015 students voluntarily praised cold calling in their anonymous open-ended course evaluations. Only one student wrote a negative comment about cold calling: "I wish the class incorporated more discussion rather than cold calling." We work deliberately to create a safe space for students to be wrong by praising risk taking and different perspectives and highlighting that being wrong is an opportunity to learn. As one student said in the focus group, "I really like how [the professor] doesn't discourage failure if you answer a question wrong. Literally everyone answers questions wrong all the time and it's completely fine. It was weird the first time, [when] you were like 'oh I got a question wrong. It's like the worst thing that has ever happened but at this point I have no idea what this graph means,' and that's okay and we move on. There's no stigma attached to admitting that you don't know something or you're wrong about something." In large-enrollment courses, an active environment can be achieved through real-time studentresponse system (clicker) questions, online polling systems, and small-group discussions, as described in multiple publications (Caldwell, 2007; Tanner, 2009; Moravec et al., 2010; Smith et al., 2011a,b).

Inherent to our approach is the philosophy that "less is more," meaning that more time is spent going in depth on fewer topics (Hoskins and Stevens, 2009; AAAS, 2011). Colleagues had raised concerns that our students would miss critical content and would not be well prepared for upper-level courses. However, upon completion of two semesters of the redesigned courses, students performed equally in upper-level courses compared with students who took the traditional introductory courses (Figure 1). In all cases, linear regression showed that introductory course grades were predictive of mean upper-level grades in biology course (Cell/Molecular non-DIBS: $\beta=0.46, F_{1,31}=49.8, p<0.001$; Cell/Molecular DIBS: $\beta=0.57, F_{1,25}=43.06, p<0.001$; Phys/Ecol non-DIBS: $\beta=0.50, F_{1,25}=80.49, p<0.001$; Phys/Ecol DIBS: $\beta=0.80$, $\left.F_{1,25}=78.89, p<0.001\right)$. These data are true for all students who took two semesters of introductory biology during the same 2-year period and later became biology majors. Most critically, despite faculty concerns that covering less material in more depth would leave students ill prepared for the major, we found no statistical difference in upper-level grades in courses taken by a mixture of students coming from redesigned and traditional introductory courses (analysis of covariance, Cell/ Molecular DIBS vs. non-DIBS: $F_{1,57}=0.08, p=0.78$; Phys $/$ Ecol DIBS vs. non-DIBS: $\left.F_{1,59}=0.40, p=0.53\right)$. It would be interesting to compare student outcomes on standardized tests such as the redesigned Medical College Admission Test and Graduate Record Examination.

A common and legitimate concern is the substantial amount of time it takes to overhaul a course. It took us 3 years to write our textbook and another 4 years to find a publisher willing to 
111 (other instructors) vs. 113 (AMC)
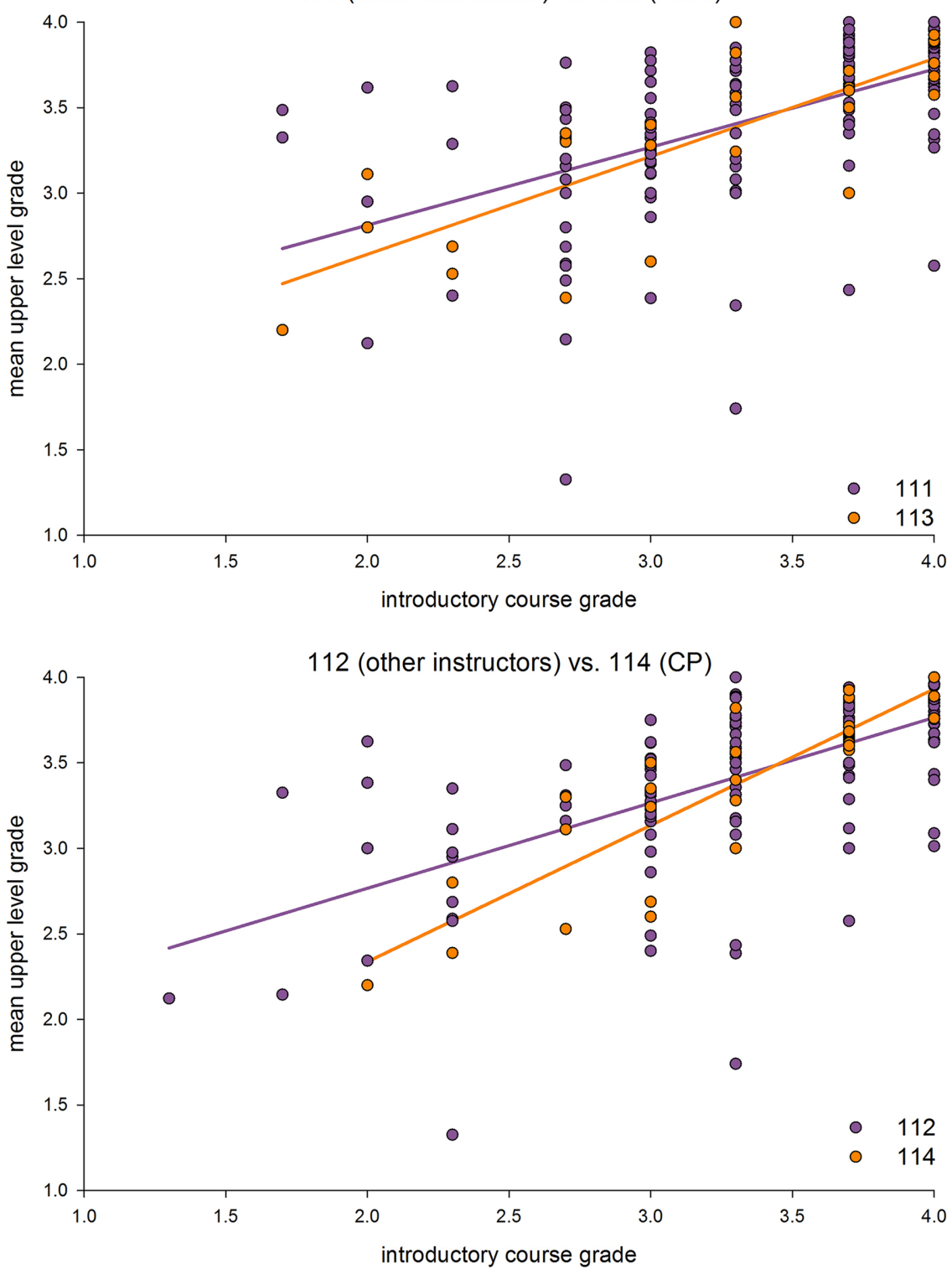

FIGURE 1. Comparison of students' final grades in 200-level biology courses as a function of their course grades in non-DIBS or DIBS introductory classes. Top: students in Cell/ Molecular DIBS (A.M.C.) vs. non-DIBS course. Bottom: students in Physiology/Ecology DIBS (C.J.P.) vs. non-DIBS course. Performance in upper-level courses was equivalent between the two course designs for both top and bottom graphs.

break with the traditional model of biology textbooks. Other faculty might want to save time and use our resources, or they can develop their own. However, we find that we and other faculty using our DIBS-teaching approach are spending much less time than we used to spend preparing for each individual class, because we are not trying to remember so many factoids (Wagner et al., 2015). In short, rather than relying on last-minute preparation and rehearsal of planned lectures, we rely on our years of experience and training and are ourselves willing to say "That's a great question. I don't know."

Our redesigned courses have been well received by students. On end-of-semester course evaluations from the Fall of 2015,
$100 \%$ of the 59 students who answered the survey made positive comments about the DIBS-teaching approach. One student said, "The main goal of the course was to make us think for ourselves and [it] was successful." Another commented, "At first, 'constructing my own knowledge' sounded like a cliché fit for an AP bio class T-shirt. But, of course, it ended up being one of the most effective learning strategies I've ever encountered. Because I was able to take my learning into my own hands, I feel much more confident in my scientific understanding and abilities. I felt less reliant upon 'being taught' and more capable of teaching myself." Though 100\% of the students made positive comments about the course, some also gave constructive criticism. For example, only two commented on a class activity in which students acted out proteins conducting signal transduction; "acting out [enzymes] and moving around did not help me visualize what was happening." However, both of these two students confirmed that they would recommend the course to a friend when prompted on the course evaluation form.

However, many of our colleagues have not embraced our approach. Two of us (C.J.P. and A.M.C.) taught the more traditional approach for more than a decade, so we are intimately familiar with it. To date, the only other Davidson faculty members to teach our version are the two newest hires, who had not invested years into refining a more traditional approach. Recently, a senior faculty member announced her intention to adopt our approach, illustrating that change among hesitant faculty can indeed happen. Perhaps we need to give our colleagues more time to consider letting go of their more familiar way of teaching.

\section{CONTENT}

Vision and Change outlined the content of the ideal introductory biology course but did not provide specifics (Table 1) (AAAS, 2011). The report recommended making substantial changes in course content to match the new learning objectives. Recommendations included making biology increasingly interdisciplinary, incorporating more mathematics and modeling, and explaining how scientific discoveries are made (NRC, 2003; AAAS, 2011). We developed Bio-Math Explorations to further enhance these three competencies. When considering how to accomplish all the objectives, we wanted our students to behave like scientists who support understanding and claims with data. Our DIBS-teaching approach parallels the research world by providing data from the primary literature to validate core concepts. The data are contextualized within a framework and a 
TABLE 1. Summary of Vision and Change core concepts and competencies

\begin{tabular}{ll}
\hline Core concepts & Core competencies \\
\hline Evolution & Apply the process of science \\
Structure and function & Use quantitative reasoning \\
Information & Employ modeling and simulation \\
Energy & Experience interdisciplinary science \\
Systems & Communicate with other disciplines \\
& Integrate science and society \\
\hline
\end{tabular}

guiding question. Our students read a description of the research question and methods and then engage the original published experimental results. Later, students are asked questions in the reading and in class to extract fundamental concepts from the data, similar to the CREATE method described by Hoskins and Stevens (Hoskins and Stevens, 2009). We faced two major challenges when assembling the data. It took a lot of searching to find data-rich figures that illustrated major points appropriate for beginning biology students. In addition, we had to provide even coverage for the core concepts and phylogenetic diversity to include plants, microbes, and nonmodel animal examples.

In testing students in a DIBS-teaching course, we wanted them to apply their interpretive skills and support their answers using experimental evidence from a "data gallery" provided as part of the test (Barsoum et al., 2013). For example, we might ask students to describe the function of a tRNA, but they also had to choose the correct supporting data from the gallery and explain how their data selections supported their answers. Sample exams are freely available online for faculty who adopt the book (Campbell et al., 2014). Giving students real data allows them to reinforce the competencies of quantitative reasoning, modeling simulations, and the interdisciplinary nature of science. DIBS-teaching addresses the Vision and Change core concepts and competencies simultaneously and puts the data back into biological sciences, which are often taught as a vocabulary discipline mastered through memorization, the antithesis of the process of science.

Our prior publication showed that students in a DIBS-teaching course learned the core concepts as well as students in nonDIBS courses, but DIBS students retained the information longer (Barsoum et al., 2013). DIBS teaching also improved student data-analysis skills that are best learned and retained through frequent practice. Though some colleagues were concerned that the new courses might discourage students, the DIBS-teaching approach has proven popular among students. On a standard course evaluation for the Fall of 2015, 52 out of 59 students $(88 \%)$ made positive comments about DIBS teaching. One student commented, "I feel a lot more comfortable, being given a graph about pretty much anything and then interpreting it after taking this [course] as opposed to before. When I would have really relied on being able to just, like, memorize facts, I think now I feel more comfortable with analyzing and interpreting data, which I think will help me more in the long run." Another said that the DIBS approach "gave [me] a very real-world perspective ... When you are doing science in the real world, you don't need to memorize all the facts ... I think it also help[ed] in terms of [my] critical thinking skills ... It really helped me in my decision to major in biology." A third student wrote, "The presentation of scientific data in the textbook allowed me to 'do science' in order to learn the material ... [These], I believe, helped me to retain a deeper understanding of the material."

\section{TECHNOLOGY}

After addressing pedagogy and content, we searched for a technology that could help students learn. Many have reported that in-class clickers enhance student learning (NRC, 2003; Caldwell, 2007; AAAS, 2011; Smith et al., 2011a,b). Clickers are a popular way to keep students engaged and give both them and instructors immediate feedback. Clicker questions can be effective tools in both large and small classrooms when used in conjunction with the principles of peer instruction (Smith et al., 2011a,b). Learn-before-lecture teaching and appropriately used PowerPoint slides are two other technology-reliant approaches that have been shown to be effective uses of an active-learning strategy (Bartsch and Cobern, 2003; Moravec et al., 2010). Online tools can facilitate modeling simulations in lab and self-paced learning (Gibbons et al., 2004).

Our two-semester introductory sequence incorporates two major technologies to expand the learning environment beyond the classroom. Our DIBS-teaching approach uses an e-textbook that students can access from any Web-ready device (Barsoum et al., 2013; Campbell et al., 2014; Prestwich and Sheehy, 2015; Wagner et al., 2015). The e-textbook provides students with embedded interactive multimedia, something not possible with printed books. We chose the Web-based Echo360 platform as an online active-learning hub where lecture slides are posted before class, students take private notes directly on slides during class, and the professor can upload short video recordings before or after class to supplement material or clarify difficult concepts. We incorporated in-class, clicker-type quizzes embedded in the presentations with aggregate student response data, which often led to in-depth small-group discussions (Tanner, 2009). Furthermore, the active-learning hub records all the slides and audio and automatically posts the video to the course website about 1 hour after class finishes. These classroom recordings allow students to listen to portions of the class they did not understand. An added bonus is that students who miss class due to illness or extracurricular activities can catch up on their own time. Despite concerns that students would skip class and listen to the recordings later, recorded classes did not erode attendance; absenteeism ranged from 0 to $10 \%$ on any given day, as it did before making/using classroom recordings. Class attendance is equally high in all of the introductory biology courses at Davidson.

There is a risk associated with adopting relatively new technologies, especially in a classroom environment, where interruptions can negatively affect student learning. The updated online active-learning hub we chose, Echo360, was relatively new and imperfect, and we discovered news bugs and glitches as we were working through the first semester of the technology's use. We spent additional time changing plans, finding workarounds, and asking the company's product design team for help. Students encountered issues too, discovering that there were word limits in the note-taking platform and a few instances of deleted and unrecoverable notes. One student 

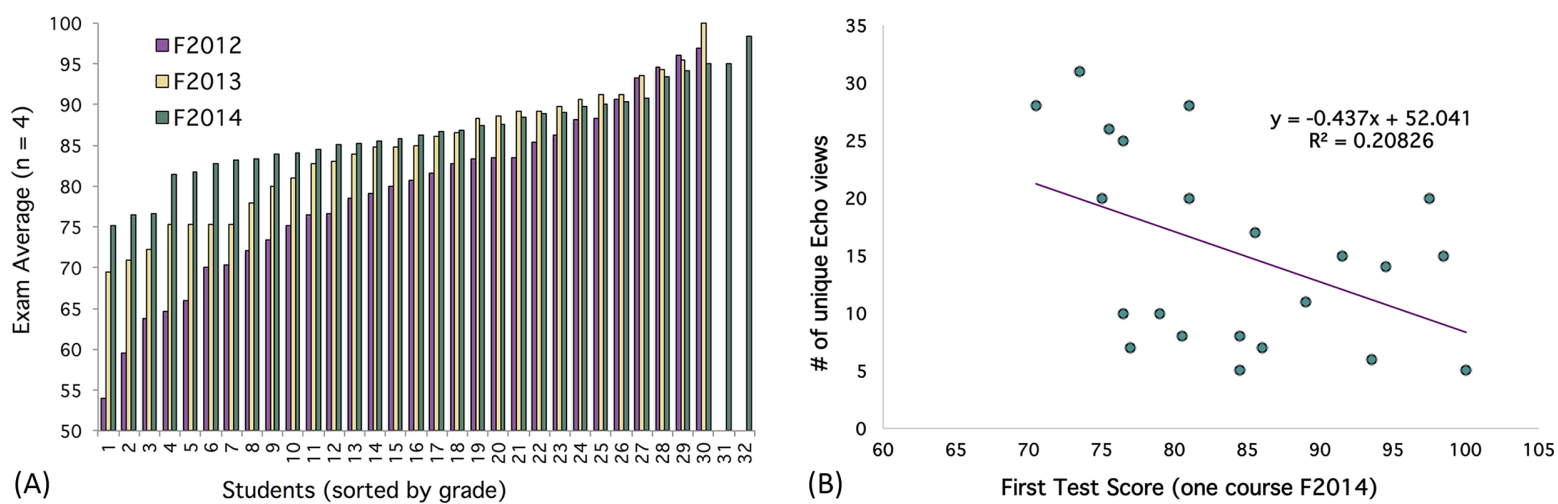

FIGURE 2. Echo360 is a useful tool that helps students improve their grades. (A) Distribution of student exam averages by year. In 2012 , before using Echo360, 47\% of students averaged below $80 \%$. Average exam grades improved from 2012 to 2014 , with averages of 79,84 , and $86.7 \%$, respectively (ANOVA $F_{289}=6.62, p=0.002$ ). The first year of Echo360 (2013), $26 \%$ of the students averaged less than $80 \%$ and in 2014 only $9 \%$ averaged below $80 \%$. (B) The number of Echo360 views per student was a negative function of the grade achieved on the first test, such that students who received lower grades were more likely to view lecture captures, presumably as a supplemental resource $\left(F_{1,20}=5.26, p=0.03\right)$.

reported in the focus group that Echo360 caused his/her computer to freeze. We spent hours troubleshooting our way through producing course quizzes. Furthermore, importing slides from PowerPoint is more cumbersome than before, and provides fewer functional features than the original slides. Quiz functions were clunky and did not provide us the resolution of student responses we wanted. As with any "improved" software, this newer version provided extra capabilities that presented new problems, especially in the analytics. Nevertheless, prior experience with a previous version and evidence of the benefit to students of using active-learning technology encouraged us to persevere, and the design team has been somewhat responsive to our requests for more resolution and ease of downloading quiz scores. Moreover, trying something new always takes effort and has some problems, even simply teaching in a new room or using a new textbook. And most importantly, if professors do not try new things in the classroom, how can we know whether they will help our students learn?

We wanted to know whether the online active-learning hub was helping students learn and perform better on our tests. We examined student test grade distributions over 3 years- 1 year before the new technology implemented and the first 2 years of its use (Figure 2A). Since the online learning hub's debut as a part of the course in the Fall of 2013, student use of it has increased. Students who performed poorly on the first test had the highest number of recorded lecture views after but not before the first test, which suggests that students who needed more help used the technology more (Figure 2B). Rather than being one technology for all students, the online learning hub appears to be a bridge across the gap that had left some students behind in the past. On Fall 2015 postcourse surveys, students rated the usefulness of the online learning hub. Many students indicated the technology was very helpful, and no one reported that it had a negative impact (Figure 3A). Thus, students who needed the technology more were more likely to use it, which is consistent with the growing number of students whose test averages were above $80 \%$ (see Figure $2 \mathrm{~A}$ ). In the Fall of 2012, before the online learning hub was adopted, $47 \%$ of students in one instructor's course (A.M.C.) had an average across their four tests of less than $80 \%$. In the first year of the
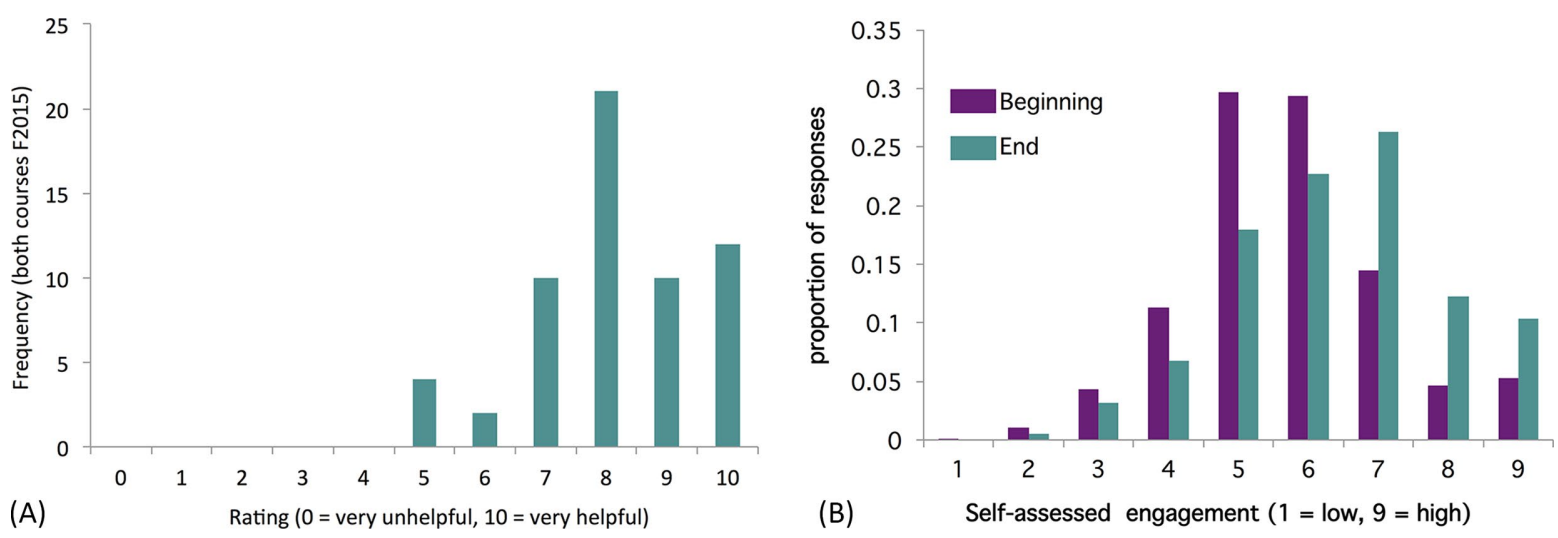

FIGURE 3. Students valued the use of technology. (A) Fall 2015 student end-of-semester rating of Echo360 in two DIBS courses. (B) Students rated their engagement with the material before and after class. Ratings were averaged across the semester and are shown as the proportion of responses for each possible rating. Survey questions used in this figure are available in the Supplemental Material. 
online learning hub (Fall 2013), 26\% of the same instructor's students averaged less than $80 \%$. In the second year of the online learning hub (Fall 2014), only 9\% of students averaged less than $80 \%$ across their four exams. While promising, our preliminary results need to be tested on many more campuses before determining the utility of this or any online learning hub, and we acknowledge that grades are an imperfect measure of student learning.

Given that many students were using the recorded lectures, it was possible that they were not fully engaged during class, although we predicted this not to be true given the flipped nature of the DIBS-teaching approach. We used in-class clicker questions to capture student self-assessed engagement at the beginning and end of every class. If students were relying on the recorded lectures, or if the DIBS-teaching approach was not working well, then engagement scores might not change from the beginning to the end of each class. On the contrary, students reported significantly higher engagement at the end of each class, on average, as summarized in aggregate data (Figure 3B, a mean increase of 0.67 on a nine-point scale $\left.[ \pm 0.3395 \% \mathrm{CI}], t_{26}=4.17, p<0.001\right)$. These data are consistent with our personal observations, because we walk around the open-style classroom and can directly view their computer screens. Colleagues who have observed our teaching have also supported and confirmed our impressions. Furthermore, our use of cold calling has an added benefit of keeping students on task and engaged.

The use of an e-textbook was the first of its kind in our biology department. Several instructors have eliminated textbooks in their upper-level courses, but no one had tried an e-textbook-only approach for introductory biology. If you ask most students, they will tell you that they prefer paper books. The adjustment period with the e-textbook was one of the technological challenges we faced with this course, because it takes time for the students to get used to the e-textbook-only format (Daniel and Woody, 2013). We encountered a range of predictions among our colleagues about how students would react to online reading assignments. At the end of the Fall 2015 semester, we surveyed students in the two DIBS-teaching classes to measure their reactions to the online textbook. Four students rated the book lower when asked to rate their feelings toward the book from the beginning to the end of the semester ( 0 = unhappy, 10 = happy). Eleven students did not change their opinions, but 44 students indicated an improved opinion of the online textbook over the course of the semester (Figure 4). On an end-of-semester survey, six students wrote negative comments about the e-textbook: four stated they still prefer paper books, and two noted occasional technical glitches with the e-textbook platform. Some students indicated their opinions on the anonymous course evaluations: two people said that the e-textbook took some getting used to, but they eventually decided they liked it; one said the readings could get a bit wordy, but overall they liked it; one wrote, "I did not like the textbook;" and one said, "I wish that the book would give more direct information about biological concepts and use the experiments as examples rather than asking us to infer all of the concepts ourselves using exclusively experimental data," which is ultimately a criticism of the DIBS-teaching style more than the e-textbook. Despite the perception that today's students are accustomed to online reading, we have noticed that many voice a preference for paper text-

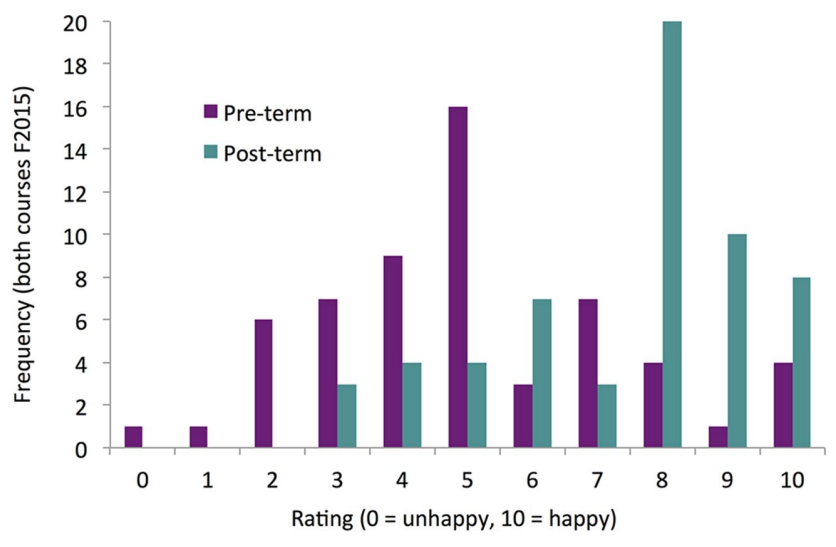

FIGURE 4. Students' opinions of online textbook increased over the semester. Students in the two DIBS-teaching courses used the e-textbook and rated their feelings about having to use an online textbook before and after the semester. Students expressed significantly more favorable opinion of the book after the semester ( $t$ test; $p=0.000$ ). Survey questions used in this figure are available in the Supplemental Material.

books. Our results indicate that preference for paper textbooks can be overcome, though we have not studied why.

Some faculty worried that too much technology would discourage students from attending class (Cardall et al., 2008). Students did not skip class knowing that they could listen to the recorded version later and in half the amount of time, since playback can be at double speed. Students recognized the value of being present and participating in class. One of the authors who was not an instructor of the courses (K.E.) conducted two focus groups from randomly selected students across the spectrum of test grades. One student said, "Echo360 was one of my favorite aspects of the course ... I loved being able to go over the slides after and before class. To me, that was crucial in my understanding of the material." Another student praised the usefulness of the recorded lecture feature: "I think it is really helpful to go to specific moments that I remember I didn't understand ... [Sometimes] working through the book or the slides [by myself] is a lost cause, but having the [recordings of the lectures for reference] as in 'oh that one time in class where [the professor] explained it really well' [is helpful], and without Echo there would be no way of going back to that and you'd just have to remember it."

\section{CONCLUSION}

The restructured, two-semester introductory biology sequence has transformed our curriculum to be better aligned with Vision and Change. In fact, when Davidson's biology department was evaluated by two PULSE (Partnership for Undergraduate Life Sciences Education) fellows as part of its PULSE certification pilot site visit, the evaluators said the DIBS course "offers a highly innovative introductory biology sequence with integration of concepts in a new approach that may be just what the authors of [Vision and Change] had in mind. Instead of traditional clustering of topics by level of organization, [the course] organizes information by [core] concept and then explores how those concepts manifest at different levels of organization." This introductory course sequence was cited 


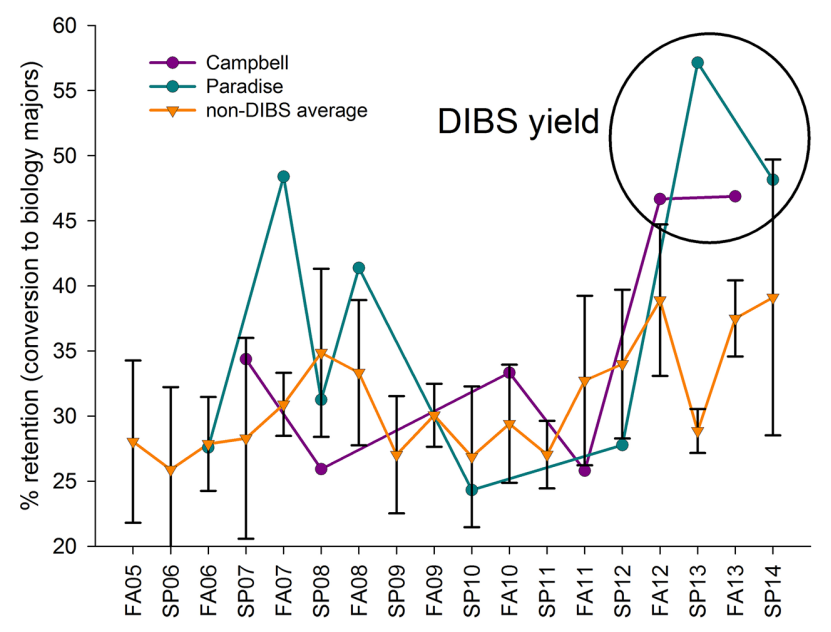

FIGURE 5. The DIBS-teaching approach increased the percentage of students who became biology majors. Percentages represent the proportion of students who took the indicated courses and subsequently declared biology as their major-all Davidson students matriculate without a declared major. Data reveal the biology-major yields of two senior instructors for the DIBS-teaching approach (A.M.C. and C.J.P.) compared with their previous yields and the average yield ( $\pm 1 \mathrm{SE}$ ) of professors not using the DIBS approach.

repeatedly in the written PULSE evaluation and contributed to the overall departmental rating of PULSE Progression Level III: Accomplished, which was the highest of all eight institutions evaluated (PULSE, n.d.). The two senior instructors (A.M.C. and C.J.P.) for the DIBS-teaching approach have seen dramatic increases in the percent of students in their courses who eventually become biology majors (Figure 5). The increased percentage of majors refutes predictions by some that the new curriculum would discourage potential biology majors.

This redesigned course using a DIBS-teaching approach not only keeps students engaged, but also changes the instructors' experiences. The biology department at Transylvania University uses the same DIBS-teaching approach. A senior faculty member there noted, "It is not uncommon to end class totally surprised by what new ideas or issues we covered in class. Because of this spontaneity, we are more engaged and responsive to the students' learning" (Wagner et al., 2015). Our experience has been replicated on other campuses that use their own iterations of active pedagogy, DIBS teaching, and appropriate integration of technology (Rowe et al., 2015).

Throughout the past 8 years, we have faced three major obstacles on our journey to design, implement, and revise our restructured courses. We faced persistent skepticism from colleagues who shared with us concerns they had about our new approach. Luckily, many of these concerns were also testable hypotheses. To address our colleagues' doubts, we collected data and found no evidence to support their concerns (as shown here and in Barsoum et al., 2013).

Another challenge is trying to fit a different introductory course sequence into an existing curriculum. The compromise was to offer two parallel tracks of introductory biology at Davidson. Thus, we offer the redesigned course (Biology 113 and
114) and the department also still offers traditional courses (Biology 111 and 112). Having two introductory course formats made our research difficult to control, because students can select their courses based on their own motivations. The third challenge was that we initially introduced this course as a team-taught course in which the biology size scales were smoothly integrated across all the core concepts over two semesters. However, team teaching added to our existing workload, so the extra time commitment became too burdensome. Furthermore, we were told clearly by colleagues around the country that they would never adopt DIBS teaching if it had to be taught as a team-led course. Therefore, we reorganized the e-textbook chapters and separated the content based on size scale. Now our book can be used in semester-long halves that are separated more traditionally into small (chapters 1-15) and big (chapters 16-30) biology.

More than 500 faculty from around the country developed the recommendations in Vision and Change. They noted that active learning is not an idealistic dream or an untested idea. It is a practical, attainable, proven instruction method that is vital to student learning and retention. Improving student learning outcomes in biology is vital to America's future. The President's Council of Advisors on Science and Technology (2012) report called for 1 million more STEM graduates to meet the growing needs of a technology-literate society. Our implementation of the recommendations in Vision and Change has produced better learning outcomes and increased student retention in the major. Though some students were initially wary about the unfamiliar class format, $100 \%$ of 59 students made positive comments on their Fall 2015 course evaluations. As one student said, "In a lot of intro classes, it's about memorizing facts and glossary terms ... it's easy to memorize something for a test but I think I'm actually learning how to use my brain and not to fill it."

Wagner et al. (2015) noted that faculty from around the country who reviewed the DIBS-teaching approach before its publication indicated that fear of change was the most common reason for not wanting to adopt this new approach. Change, however, is necessary for the growth of the biology community. If we do not adopt the best practices of teaching, we are doing more to harm some of our students than to help them (Freeman et al., 2014). Our implementation is only one example of fulfilling the recommendations established by Vision and Change. Educators wishing to improve their introductory courses do not have to invent new methods, but they do have to be willing to change. We hope our experience can encourage many more to embrace the change and fulfill the vision. We did not collect our data from controlled experiments, which is what most biology faculty would like to see. We also recognize that no data will be good enough to convince some to change. No doubt many faculty will think, "I don't want to change and you can't make me." Our advice to innovators and early adopters who encounter this resistance? Don't try to change them. If you change your own ways and restructure your course to benefit the students, you have paved the way for others to follow when they are ready. In the end, the students are the best lobbyists for change. Once they have experienced the redesigned course and its benefits, word will get around, and the demand for these types of courses will increase. Our example demonstrates that an overhaul is possible and the results are worth the effort. If you don't believe us, just ask our students! 


\section{ACKNOWLEDGMENTS}

We thank our students for participating fully in a new approach to introductory biology. We also thank Dr. Laurie Heyer for her work on Bio-Math Explorations in the e-textbook. Support was provided by Howard Hughes Medical Institute grant 52006292 to Davidson College and the James G. Martin Genomics Program at Davidson College.

\section{REFERENCES}

American Association for the Advancement of Science (2011). Vision and Change: A Call to Action, Final Report, Washington, DC. http:// visionandchange.org/finalreport (accessed 2 September 2015).

Barsoum MJ, Sellers PJ, Campbell AM, Heyer LJ, Paradise CJ (2013). Implementing recommendations for introductory biology by writing a new textbook. CBE Life Sci Educ 12, 106-116.

Bartsch RA, Cobern KM (2003). Effectiveness of PowerPoint presentations in lectures. Comput Educ 41, 77-86.

Caldwell JE (2007). Clickers in the large classroom: current research and best-practice tips. CBE Life Sci Educ 6, 9-20.

Campbell AM, Heyer LJ, Paradise CJ (2014). Integrating Concepts in Biology, 1st ed. Davie, FL: Trunity. www.trunity.com/products/digital-textbooks/ integrating-concepts-in-biology

Cardall S, Krupat E, Ulrich M (2008). Live lecture versus video-recorded lecture: are students voting with their feet? Acad Med 83, 1174-1178.

Dallimore EJ, Hertenstein JH, Platt MB (2012). Impact of cold-calling on student voluntary participation. J Manag Educ 37, 305-341.

Daniel DB, Woody WD (2013). E-textbooks at what cost? Performance and use of electronic v. print texts. Comput Educ 62, 18-23.

Flaherty C (2016). Professors can learn to be more effective instructors. Inside Higher Ed. www.insidehighered.com/news/2016/02/10/new-study -suggests-faculty-development-has-demonstrable-impact-student - learning (accessed 26 February 2016)

Freeman S, Eddy SL, McDonough M, Smith MK, Okoroafor N, Jordt H, Wenderoth MP (2014). Active learning increases student performance in science, engineering, and mathematics. Proc Natl Acad Sci USA 111, $8410-8415$

Gibbons NJ, Evans C, Payne A, Shah K, Griffin DK (2004). Computer simulations improve university instructional laboratories. Cell Biol Educ 3, 263269
Gross D, Pietri ES, Anderson G, Moyano-Camihort K, Graham MJ (2015). Increased preclass preparation underlies student outcome improvement in the flipped classroom. CBE Life Sci Educ 14, ar36.

Hoskins SG, Stevens LM (2009). Learning our L.I.M.I.T.S.: less is more in teaching science. Adv Physiol Educ 33, 17-20.

Jensen JL, Kummer TA, Godoy PDdM (2015). Improvements from a flipped classroom may simply be the fruits of active learning. CBE Life Sci Educ $14, \operatorname{ar} 5$.

Moravec M, Williams A, Aguilar-Roca N, O'Dowd DK (2010). Learn before lecture: a strategy that improves learning outcomes in a large introductory biology class. CBE Life Sci Educ 9, 473-481.

National Research Council (NRC) (2000). How People Learn: Brain, Mind, Experience, and School, expanded ed., Washington, DC: National Academies Press.

NRC (2003). BIO2010: Transforming Undergraduate Education for Future Research Biologists, Washington, DC: National Academies Press.

President's Council of Advisors on Science and Technology (2012). Engage to Excel. Undergraduate STEM Education Report

Prestwich KN, Sheehy AM (2015). Integrating concepts in biology: a model for more effective ways to introduce students to biology. CBE Life Sci Educ 14, fe3.

PULSE (n.d.). PULSE Progression Levels Announced! www.pulsecommunity .org/page/pulse-progression-levels-announced (accessed 26 February 2016)

Rowe MP, Gillespie BM, Harris KR, Koether SD, Shannon L-JY, Rose LA (2015). Redesigning a general education science course to promote critical thinking. CBE Life Sci Educ 14, ar30.

Smith MK, Trujillo C, Su TT (2011a). The benefits of using clickers in small-enrollment seminar-style biology courses. CBE Life Sci Educ 10, $14-17$

Smith MK, Wood WB, Krauter K, Knight JK (2011b). Combining peer discussion with instructor explanation increases student learning from in-class concept questions. CBE Life Sci Educ 10, 55-63.

Tanner KD (2009). Talking to learn: why biology students should be talking in classrooms and how to make it happen. CBE Life Sci Educ 8 89-94.

Uno GE (1999). Handbook on Teaching Undergraduate Science Courses: A Survival Training Manual, Fort Worth, TX: Saunders College.

Wagner JD, Campbell AM, Sly BJ, Paradise CJ (2015). An active textbook converts "vision and tweak" to Vision and Change. CourseSource. http:// coursesource.org/courses/an-active-textbook-converts-vision-and -tweak-to-vision-and-change (accessed 22 September, 2016). 